\title{
Reinforcing and Toughening Effect of Plant Fine Roots on the Soil
}

\author{
YunYan Zhou, Kun Xu, JianPing Chen, XiaoMei Wang \\ China University of Geosciences, Wuhan, China \\ Zhouyunyan369@sohu.com, 506977364@qq.com, chenjp6688@163.com, tjcjn@163.com
}

\begin{abstract}
In the prevention of soil erosion, vegetation is an economical and environmentally friendly control methods, the most basic indicators of the plant protection design is solid soil function of plant roots. From the perspective of composite the fine rooted soil as a kind of special composite materials, the fine roots as the reinforcement material, using fracture mechanics theory the paper analyzes the enhancements and toughening effect of roots on the soil in order to illustrate the mechanism of solid soil and protection slope of plant roots. At different stages of loading the bridging effect of root has different manifestations, during the micro-crack propagation the bridging effect of root as follows: an equivalent closure role imposed on the expansion of micro-cracks, the stress concentration of micro-cracks cutting-edge can be passivated, the stress distribution more uniform, increasing the shear capacity of the soil; during the macro-crack propagation the bridging effect of root as follows: the roots across crack gradually pulled out to prevent cracking or crack propagation, crack propagation must consume a large amount of energy, thereby increasing the strength and toughness of the composite soil. Due to matrix cracking the load transferred to roots, by stress proliferation the load is passed to the soil surrounding roots. while its stress reached peak, soil had strain strengthening characteristics with the strength, toughness and plastic of composite soil having been greatly improved. Finally, it was verified by numerical simulation and laboratory test of the direct shear tests.
\end{abstract}

Index Terms - root-soil complex, shear strength, toughness, plasticity

\section{Introduction}

Our country is one of the most serious soil erosion in the world. So far, soil erosion area in China reaches 3.5692 million $\mathrm{km}^{2}$, accounting for $37.6 \%$ of the total land area. Classified by soil erosion intensity, mild and moderate soil erosion area, which takes large part of that across the nation, is up to $68.6 \%$ [1].Among them, the shallow surface landslides, rainwater erosion, wind erosion are the major routes of soil erosion. Soil erosion destroy agriculture production to a large extent, make the ecological environment deteriorated gradually, bring about more and more frequent droughts and floods and seriously disturb the safe operation of water conservancy, electricity transportation and other facilities in our country, which is not only to make it difficult to people's work and life, but also caused a serious constraint on our economic development. In order to preserve the interests of the people and the sustainable development of the national economy, our authorities take effective control measures. So as to reinforce the slope, while to achieve the rapid recovery of the slope vegetation and protect the ecological environment, the slope protection technology by vegetation has been widely used and has gradually become an inevitable trend in recent years. For a long time science and practice has confirmed that the vegetation is always the most positive factor to prevent soil erosion. Vegetation is an economical and friendly prevention measures. It plays an irreplaceable role which other engineering measures not do such as improving ecological environment, limiting soil erosion, conserving water and stabilizing slopes[2]. And the most basic indicators of plant protection design are the function of slope stability by plant roots. Therefore, it is necessary and urgently required to carry out the systemic study of reinforcement mechanism and effect on the slope surface soil by plant roots.

It has been recognized that plant roots can improve soil strength and stability and stabilize slope. Many scholars at home and abroad have done a lot of research on the mechanism of slope stability by plant roots, and achieved some results[2-9], mainly as that roots increase soil shear strength index value, anchor role of thick roots and reinforced function of fine roots, while some scholars have suggested the concept of root-soil composite. But the mechanism on roots increment soil strength and stability not clear, theoretical research is still far behind engineering application of vegetation for slope protection. From the perspective of the fine rooted soil as a kind of special composite material, the fine roots as the reinforcement material, using fracture mechanics theory the paper analyzes the enhancements and toughening effect of roots on the soil in order to illustrate the mechanism of solid soil and protection slope of plant roots.

\section{Reinforcing and Toughening Effect of Plant Roots on the Soil}

Although the soil in slope is brittle material, it is necessary that the soil must undergo the process of the initiation, growth and perforation of local cracks before the total destroy and the landslide, only to detect and observe this phenomenon is often difficult[10]. A large number of fine roots of plant, such as lateral root and fibrous root, are interwoven into a network, and with a certain degree of tensile strength. They form a special kind of composite together with soil through friction, occlusion and adhesion with the soil, which is called root-soil composite, where the soil is matrix material and roots the reinforcement material. These roots like steel fibers with the role of resistance crack and bridging to the soil, thereby improving the strength, plasticity and toughness of the soil. And some roots can deeply roll, such as votive reach the most up to $5-6 \mathrm{~m}$ below the surface. Therefore, the roots not only protect soil surface effectively, but also can 
control the displacement of the shallow soil, resist soil block sliding and increase the slope stability effectively.

The Role of Root Bridging. The root bridging has different manifestations in the micro-crack stage and soil macro-crack expansion phase.

(1)Micro-crack stage. With increased load the shear stresses of the soil can locally exceed soil peak strength, then engendering the trend of locally relative sliding and cracking, while the roots in the soil will prevent the process, which is called the role of root bridging. Roots will bear part of the load and the shear stress of the soil will be gradually transferred to the roots in tension. An equivalent closure role imposed on the expansion of micro-crack to produce a reverse stress field in the tip of micro crack, the stress concentration of the tip of micro-cracks can be passivated, the stress distribution more uniform. And the further expansion of micro-cracks constrained, the soil to continue crack must bear load more, so increasing the shear strength of the soil.

(2)Macro-crack expansion stage. Macro-crack often expanded through the roots. After the matrix crack with increased load, roots stretched across the crack and bridged up the cracks to prevent them further expansion and cracking, which is the role of root bridging shown in Figure 1.The roots across the crack will bear the load and maintain the crack slow expansion, and thus the matrix also maintained a certain amount of residual stress in the fracture plane. with the crack expansion, the residual stress in the fracture plane will be gradually reduced, while the roots continue to bear bigger load because the roots great tensile strength and big deformation capacity until the roots broken or pulled out from the matrix. Therefore, the role process of the roots bridging is that the roots pulled out gradually in order to prevent cracking or crack propagation. In the whole process of crack expansion, it is necessary to consume the large amounts of energy because the roots continue to be pulled out, thereby increasing the strength and toughness of the composite soil, so the roots played a significant reinforcing and toughening effect on the soil.

Strain Strengthening Characteristics of the Root-soil Composite. If the amount of roots in the soil is large enough, when load increased to the soil peak strength and matrix cracking, the vertical and horizontal distribution roots can bear the load transferred from the cracking matrix, which not immediately pulled out or broken but transferring shear stress in the soil to root tensile stress with the help of friction and cohesion of root-soil interface. And by stress diffusion the load is transferred to the soil surrounding roots to make the surrounding soil also mobilized to resist shear, so that the further expansion of cracks is restrained. With the deformation increasing, the tensile stress of mobilized root gradually increasing, the roots bearing greater load, so that the root-soil composite can bear a greater load. With continually increased load, the degree of the mobilized soil strength improves gradually, When the soil strength reaching its peak strength, the matrix crack again in the other section that forms a multicracking phenomenon. At the moment, the deformation curve showing the trend of strain hardening, the roots can bear a greater load until the peak load when following the instability extension of the crack and shear failure, as shown in Fig. 2. Visibly, due to the presence of roots, while its stress reached the peak strength, the soil had strain strengthening characteristics with the strength, toughness and plasticity of composite soil having been greatly improved.

Fig. 2 shows the in-situ shear test result of rooted soil by Fannin[11] (2005) and the effect of roots to stress-strain relationship of the soil. In the diagram, black square point represents the stress-strain relationship of the measured rooted soil. If the strength of soil and roots separated, the green curve represents the stress-strain relationship of the non rooted soil while the brown curve representing the effect of roots. There are two distinctly separated shear stress peaks from Fig. 2, the first peak provided by the soil shear strength while the second provided by the tensile resistance of the root, and two peaks in the different displacement, the peak strength of the root-soil composite occurs in the relatively larger displacement. Seen from Fig. 2, due to the presence of roots, the deformation curve of the root-soil composite shows a clear trend of strain hardening with the strength, toughness and plasticity of it having been greatly improved.

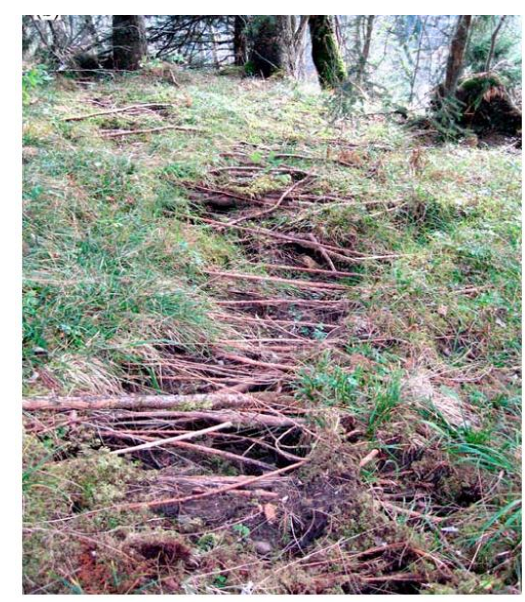

Fig.1 Roots stretched across a crack (photo by U. Hunziker, belop GmbH, Switzerland)[10]

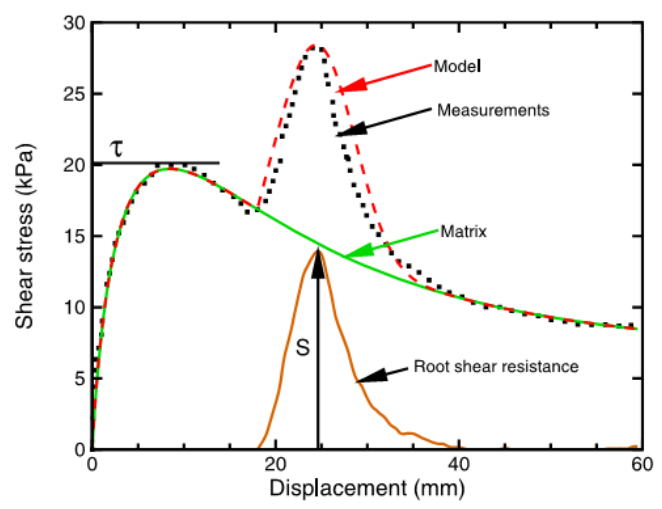

Fig.2 The stress-strain behavior of soil of an in situ shear test by Fannin et al[11] 


\section{Numerical Simulation Confirmation}

Numerical Simulation. To study the soil enhancement by roots, Slobodan ${ }^{[12]}$ in 2011 had used finite element analysis to conduct numerical simulation of the process of direct-shear test of both the soil with roots and without roots, the author of this paper also utilized the finite element software Plaxis to simulate direct-shear test and got the similar results. In the simulation, the entire soil with roots is dispersed for three different types of unit: soil unit, root unit and root-soil interface unit. The soil unit adopts triangular element with ideal elastoplasticity to simulate. Fine and intact roots have a great tensile strength but small flexural stiffness, only in the axial deformation, so one-dimensional bar element is adopted. The root-soil interface unit adopts the three-node line element with the elastoplasticity to simulate. The direct shear test simulation results of both the soil with roots and without roots Shown in Figure 3 contains deformed mesh, shear stress distribution, plastic point distribution and distribution of axial forces in the roots. In Figure 3 (a) for the direct shear simulation of the non-rooted soil, (b) for the direct shear simulation of the single-rooted soil, (c) for the direct shear simulation of the multi-rooted soil. The shear stress changed in the range of $-40 \sim 0 \mathrm{kN} / \mathrm{m}^{2}$, the blue represents the least absolute value while the red represents the largest.

(a) non rooted
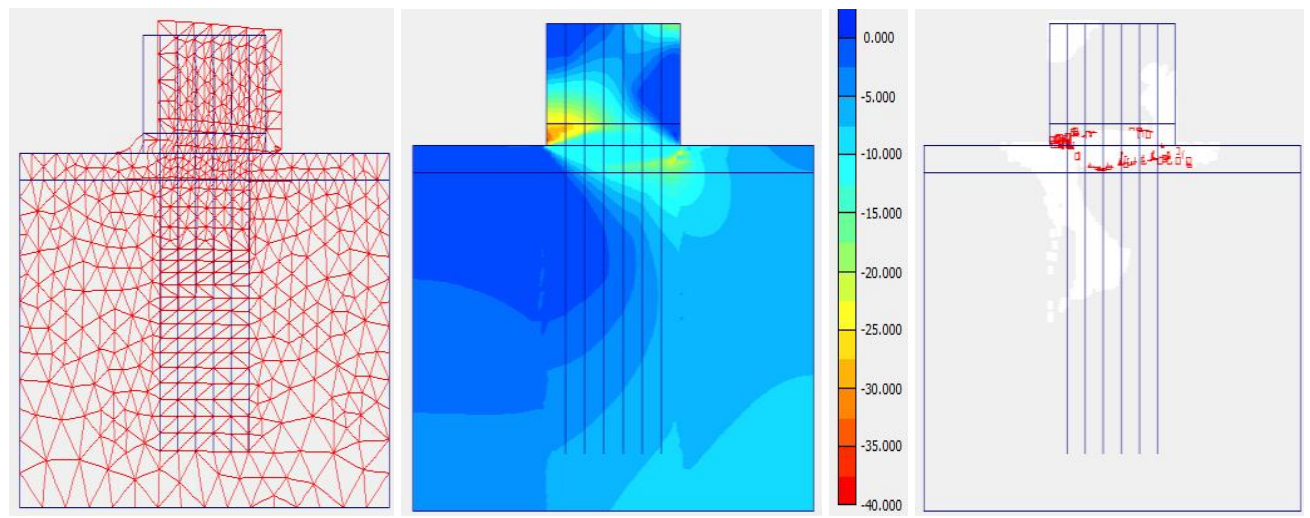

(b) single-rooted
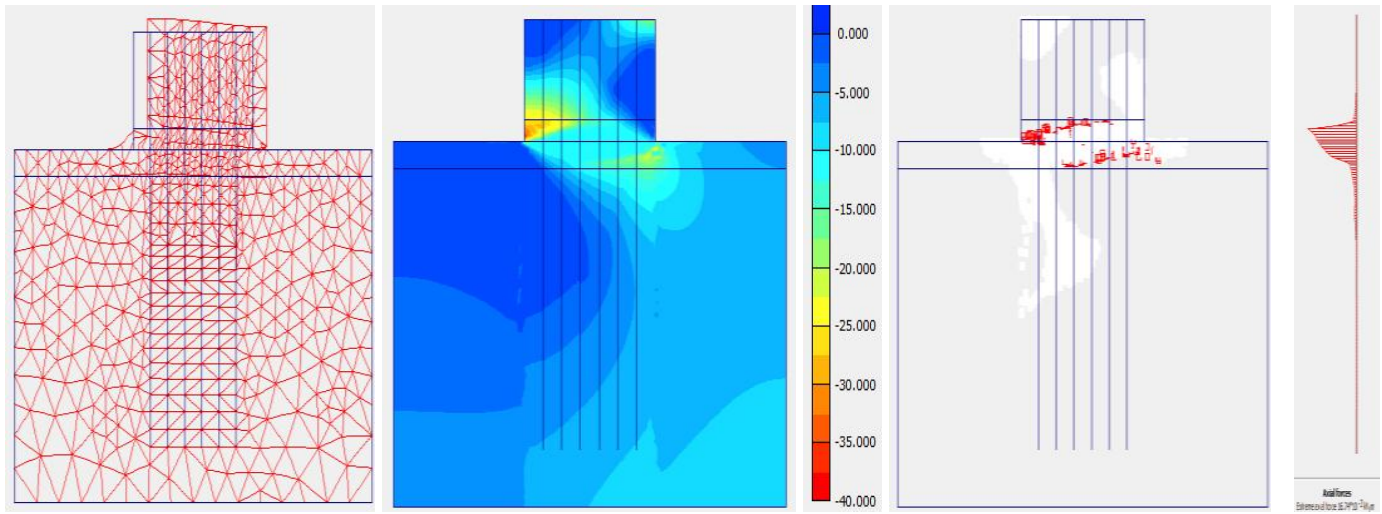

(c)multi-rooted
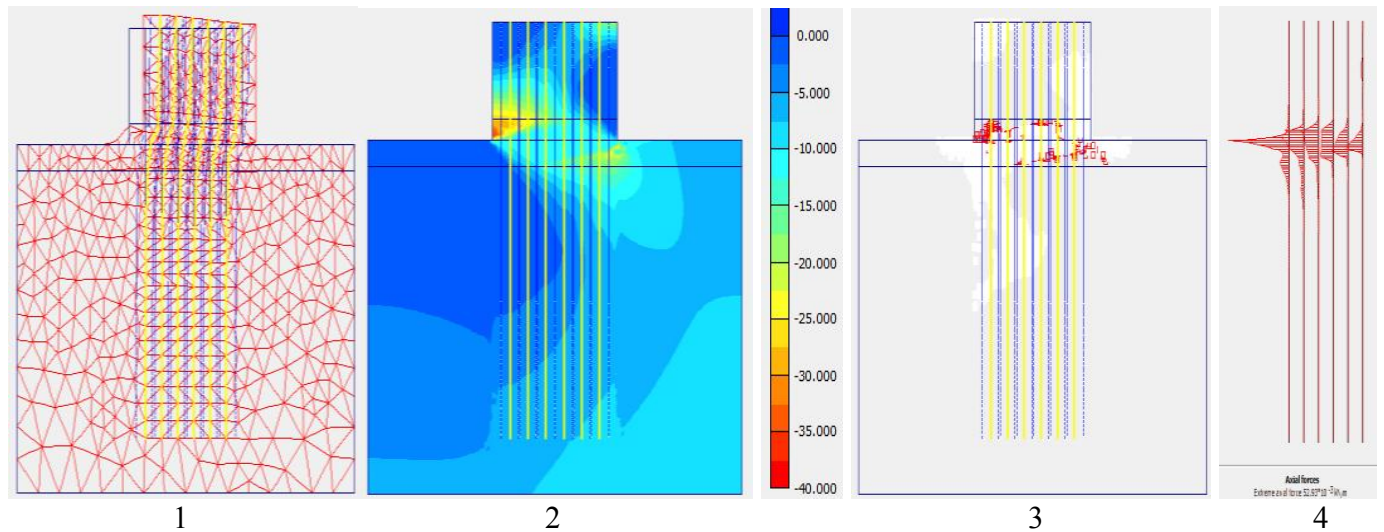

Fig.3 Deformed mesh (1), stresses distribution(2), plastic point distribution (3) and axial forces in the roots (4) for (a) non rooted,(b) single-rooted, (c)multi-rooted direct shear model 
Results Analysis. Seen from stress distribution in Figure 3 , the maximum stress concentration of non-rooted soil appears in the interface between the soil block up and down, namely the pre-shear plane closed to the load side, where will be first damaged and cracked in the direct shear process. However, the roots across the reservation sliding plane have bridging effect on the soil with retarding the process. Roots will bear part of load and the shear stress of the soil will be gradually transferred to the roots, so that the stress field in reservation slipping surface is more continuous and uniform, and the stress concentration of the tip of micro-crack can be passivated. From the stress distribution shown in Figure 3 b, c, the stress concentration in the reservation sliding surface in the soil with roots is diffused with the red region of the edge going fading and the maximum stress becoming smaller, the further cracking of the soil restrained, so the soil to continue to crack must bear greater direct-shear load. Therefore, the existence of root improves the soil anti-shear capacity.

In the process of direct shear, with the increased displacement, the upper part of the clod will slide relative to the lower part. The deformation modulus of the root and soil are quite different, the roots across the sliding surface will offer staggering displacement to make them elongation as shown in 1 of Figure 4. The root produces tensile stress by its elongation and has the trend of being pulled out, and the friction and adhesive force of the soil effecting on the root surface prevent the root pulled out, accordingly, the root is mobilized to resist shear and its result can be reflected by the maximum axial force of the root. As 4 of Figure 4 shows, the maximum axial force of the root in multi-rooted soil produced in the shearing process $\left(52.93 * 10^{-3} \mathrm{KN} / \mathrm{m}\right)$ is three times as large as the maximum axial force in the single-rooted soil $\left(16.74 * 10^{-3} \mathrm{KN} / \mathrm{m}\right)$. By the effect of friction and interlocking between the root and soil, the shear stress in the potential sliding surface converted into the root tensile stress, the roots share part of the stress in the soil and transfer it to the soil surrounding roots by Stress diffusion to make the surrounding soil mobilized to resist shear. Shown in 2 of Figure 4, the shear stress distribution of the lower part of the soil with roots in the shearing process is more widely than the distribution of the non-rooted soil. Deep blue area (absolute value is low) gradually become smaller, with the color gradually changing from dark to light and to light-green, the absolute value gradually becoming larger, so more soil strength is mobilized, and the lower part of the multi-rooted soil has larger fully mobilized area. So with the same displacement, the soil with roots can bear greater shear load, the shear capacity of the soil increased.

In the plastic distribution figure, the red square represents the point where the shear stress reached its shear strength, while white square represents the point with plastic deformation. Seen from 3 of Figure 4, the plastic point distribution area of the soil with roots (the white area in the top clods and bottom) gradually become larger than the non-rooted soil, the number of plastic points keeping on increasing. That is, before the continuous sliding surface emerges, the plastic deformation of the soil with roots continues to increase in the shearing process with the toughness and plasticity of the soil having been improved.

\section{Experimental Study}

Experimental Design. In order to explore the reinforcing and toughening effect of the roots on the soil, with the nonrooted soil and a variety of root-soil composites with different root biomass of the Amorpha, the samples had been done the direct shear test respectively. This experiment as a reference to the slope protection on the south of Yu jiashan in the campus of Huazhong University of Science and Technology, since the slope soil containing gravelly soil, this test measurement uses remodeled soil samples with the height for $2 \mathrm{~cm}, 6.1 \mathrm{~cm}$ in diameter. The soil in the test was selected in the field and the samples which were sieved $\leq 2 \mathrm{~mm}$ particles were being remodeled, Amorpha roots in the slope which were growing well were accepted as the sample root. According to the results of actual survey, combined with the specifications of the sample and the size effect to take into account, select the $0.8 \mathrm{~mm}-2 \mathrm{~mm}$ in diameter class of Amorpha roots for test. The Amorpha roots taken back from the wild and cutted into $2 \mathrm{~cm}$ root segment, then following the root content, put the Amorpha roots segment in the middle of the soil column vertically. The following table 1 detailed the design of samples in the test. Here, the root content is represented by the root volume ratio which means the percentage of the root volume occupied in the unit volume of root-soil composite.

Table 1 Sample Design

\begin{tabular}{|c|c|c|c|c|c|}
\hline \multirow[b]{2}{*}{ Sample Type } & \multicolumn{3}{|c|}{ Root Content } & \multirow{2}{*}{$\begin{array}{c}\text { Moisture } \\
\text { Content } \\
(\%)\end{array}$} & \multirow{2}{*}{$\begin{array}{c}\text { Dry } \\
\text { Density } \\
\left(\mathrm{g} / \mathrm{cm}^{3}\right)\end{array}$} \\
\hline & $\begin{array}{c}\text { Diameter } \\
(\mathrm{mm})\end{array}$ & $\begin{array}{c}\text { Root } \\
\text { Number }\end{array}$ & $\begin{array}{c}\text { Volume } \\
\text { Ratio (\%) }\end{array}$ & & \\
\hline $\begin{array}{c}\text { Non rooted } \\
\text { Soil }\end{array}$ & 0 & 0 & 0 & $17 \%$ & 1.45 \\
\hline \multirow{3}{*}{$\begin{array}{c}\text { Root-soil } \\
\text { Composite } \\
\text { with Amorpha }\end{array}$} & 0.8 & 5 & 0.09 & $17 \%$ & 1.45 \\
\hline & 0.8 & 10 & 0.178 & $17 \%$ & 1.45 \\
\hline & 1.8 & 2 & 0.18 & $17 \%$ & 1.45 \\
\hline
\end{tabular}

Adopt 100kpa, 200kpa, 300kpa, 400kpa four kinds of vertical pressure respectively in the shearing, control the shear rate for $0.1 \mathrm{~mm} / \mathrm{min}$, the curves of shear stress and shear displacement of each sample shown in Fig. 4.

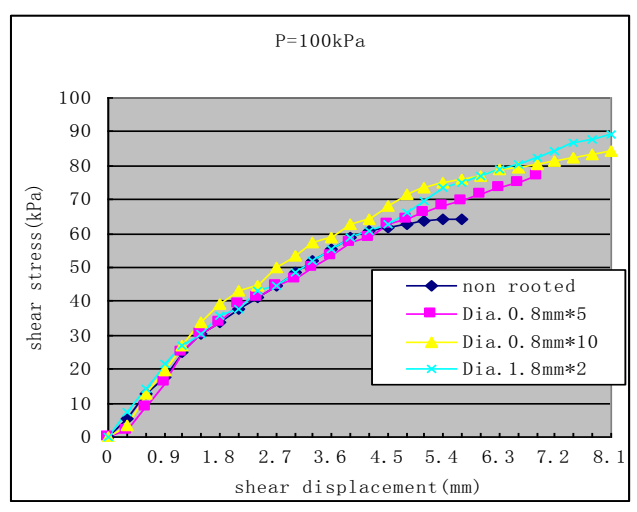



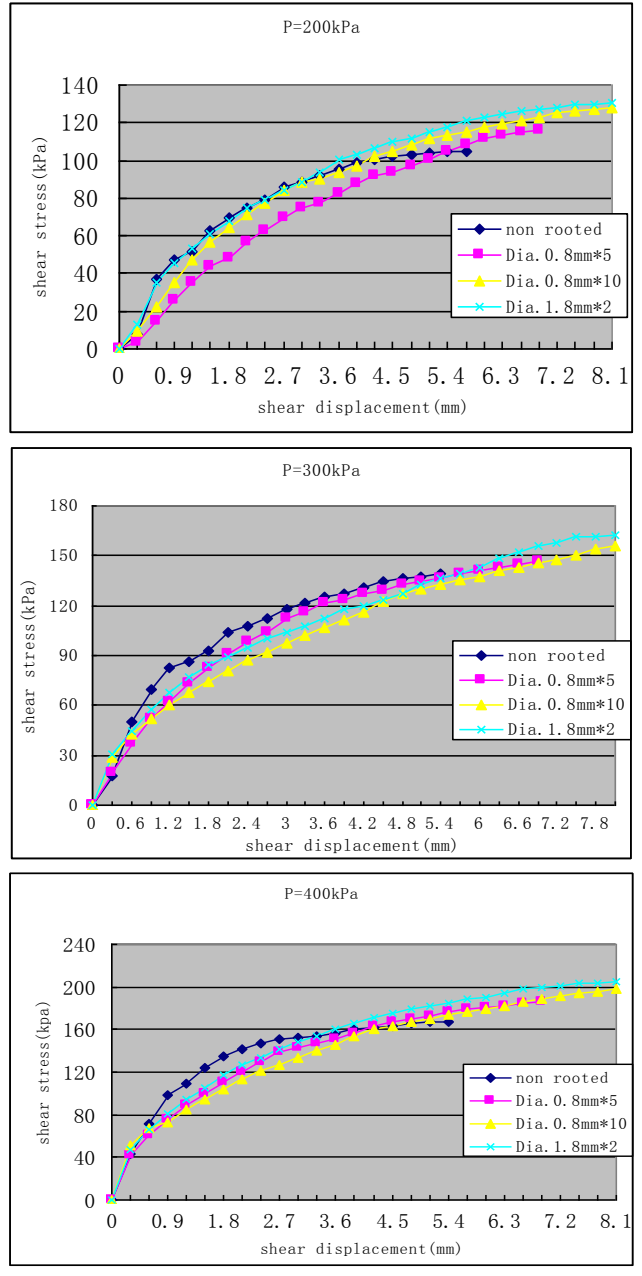

Fig. 4 shear stress and shear displacement curve of non rooted soil and Amorpha root-soil composite

Reinforcing and Toughening Effect of the Roots on the Soil. Toughness can be defined as the material performance of energy absorption under load until destruction. Fracture toughness can be considered as the energy consumed to resist fracture failure caused by the crack instability ${ }^{[13]}$, and it characterizes the material ability to prevent fracture. Here, to the Amorpha root-soil composite samples for direct shear test, when shear failure occurring along the reservation section, similarly introduce the concept of fracture toughness to characterize the shear resistance capacity of the soil with roots. The fracture toughness of the root- soil composite can be measured by its energy dissipation in the shear process (type II crack growth) and can be obtained by the area below the 0$\tau_{\max }$ phase of shear stress-shear strain curves of the root-soil composite.

Shown in Figure 4, the stress peaks of the root-soil composites in four different vertical pressure conditions are all greater than the stress peak of non rooted soil due to the presence of roots, so the roots increase the shear stress of soil. In addition, following the increases of root content and root volume ratio in four different vertical pressure conditions, the stress peaks increase. Also seen in Figure 4, the area below the shear stress-shear strain curves of root-soil composites in four different vertical pressure conditions larger than the area of non rooted soil, it also means that the fracture toughness of root-soil composite is larger than the non rooted soil and rootsoil composite greater resistance to shearing than the non rooted soil. It explains that the existence of the root can increase the fracture toughness of the soil and improve the ability to resist shearing of the soil.

Impact of Roots on the Soil plasticity. Seen from the shear stress-shear strain curves in Figure 4, in four different vertical pressure conditions, before reaching the peak strength, the soil with roots occurs more shear displacement than non rooted soil which means more slippage, so that the root-soil composite present the characteristics of plasticity. And under the four different vertical pressure, the displacement value and slippage of the root-soil composite in the shearing increases along with the increase of root content and root volume ratio.

\section{Conclusion}

The soil with roots(fine root) as the root-soil composite, the fine roots as the reinforcement material, using fracture mechanics theory the paper analyzes the role of resistance crack and bridging of roots on the soil to illustrate the mechanism of solidifying soil by roots. The fine roots across the potential fracture plane play an important role in resistance crack and bridging to make the root-soil composite slowly cracking with the increased load and showing the characteristics of plasticity. So the purpose is achieved that reinforce and toughen the soil, improve the anti-shear capacity of the soil and increase the slope stability. The conclusion has been validated by numerical simulation and test. The study of plant roots reinforcement soil and stability slope which still is a new field is developed in the last ten years. To study in depth the effect of plant root on stabilization soil and prevention soil erosion by means of multi-disciplinary and multi-field research, will play an important role in prevention of soil erosion, the ecological environment restoration and reconstruction and achieving the sustainable development strategy.

\section{Acknowledgements}

This work was financially supported by the National Natural Science Foundation of China (41102228) and Hubei Provincial Communications Department projects (2004056061).

\section{References}

[1] Z. G. Li: China Soil Erosion Status and dynamic changes. Soil and Water Conservation in China Vol. 12 (2008), p.7-10.

[2] L.H. Chen, X.X. Yu, W.F. Shong and X.P. Liu: soil reinforcement by tree root(Science Press Publications, Bei Jing 2008).

[3] X.P.Liu , L. H. Chen, W. F. Song: Study on the shear strength of forest root-loess composite. Journal of Beijing Forestry University Vol. 28-5 (2006), p. 67-72.

[4] C. L. Sao, H. L. Shun, Z. R. Yang, et al: Interactional mechanical characteristics of rock-substrate-root system. Chinese Journal of Rock Mechanics and Engineering Vol. 24-12 (2005), p. 2074-2081. 
[5] J. J. Roering, K. M.Schmidt, J. D. Stock, et al: Shallow landsliding, root reinforcement, and the spatial distribution of trees in the Oregon Coast Range. Canadian Geotechnical Journal Vol. 40 (2003), p. 237253.

[6] S. J. Martel: Mechanics of landslide initiation as a shear fracture phenomenon. Marine Geology Vol. 203 (2004), p. 319-339.

[7] E. Comino, A. Druetta: The effect of Poacae roots on the shear strength of soils in the Italian alpine environment. Soil Tillage Res. Vol.11 (2009), p. 006

[8] J.N. Norris: Root reinforcement by hawthorn and oak roots on a highway cut slope in southern England. Plant Soil Vol. 278(2005), p. 43-53.
[9] B. B. Gian, A.C. Enrico, E. Thomas: Root cohesion of forest species in the Italian Alps. Plant Soil Vol. 324 (2009), p. 71-89.

[10] D. Cohen, P. Lehmann, D. Or: Fiber bundle model for multiscale modeling of Hydromechanical triggering of shallow landslides. Water Resources Vol. 45 (2009), W10436.

[11] R.J. Fannin, A. Eliadorani and J.M.T. Wilkinson: Shear strength of cohesionless soils at low stress. Geotechnique Vol. 55 (2005), p. 467478.

[12] B. M. Slobodan, S. Alexia, V.B. Rens, et al: Simulation of direct shear tests on rooted and non-rooted soil using finite element analysis. Ecological Engineering Vol. 37 (2011), p. 1523- 1532.

[13] S. Z.Yin: Fracture injury theory and applications (Qing hua University Press Publications, Bei Jing 1992). 